GU J Sci, Part C, 5(4): 223-234 (2017)

Gazi Üniversitesi
Fen Bilimleri Dergisi
PART C: TASARIM VE TEKNOLOJI
dergipark.gov.tr/http-gujsc-gazi-edu-tr

\title{
3 Serbestlik Dereceli Bir Robot Kolun Bulanık Mantık ve PID ile Kontrolü
}

\author{
Korhan KAYIŞLI ${ }^{1}$, Muammer UĞUR ${ }^{2}$ \\ ${ }^{I}$ Nişantaşı Üniversitesi, Mühendislik Mimarlık Fakültesi, Elektrik Elektronik Mühendisliği Bölümü, Maslak, Sarıyer/ISTANBUL \\ ${ }^{2}$ Kırklareli Üniversitesi, Teknoloji Fakültesi, Mekatronik Mühendisliği Bölümü, KIRKLARELI
}

\begin{abstract}
$\ddot{\mathbf{O}} \mathbf{z}$
Makale Bilgisi

Basvuru: 25/09/2017

Düzeltme: $14 / 12 / 2017$

Kabul: $14 / 12 / 2017$

Günümüzde robot kolları birçok endüstriyel uygulamada yaygın olarak kullanılmaktadır. $\mathrm{Bu}$ noktada, sağlık gibi alanlarda kullanılan robotlarda ise yüksek hassasiyetli kontrol işlemlerine ihtiyaç duyulmaktadır. Bu yüzden robota uygulanan kontrol yöntemi de önem arz etmektedir. Bu çalıșmada ise üç serbestlik dereceli bir robotun uç ișlevcisine değișken kuvvet uygulanmıș ve dayanıklılığı test edilmiştir. Bu işlem için PID kontrol ve bulanık mantık kontrol yöntemi kullanılmıştır. Benzetim ortamında tasarımı ve simülasyonu gerçekleştirilen robot kolunun bulanık mantık ve klasik PID ile kontrolü sağlanmış, sonuçlar karşılaştırmalı olarak sunulmuştur.
\end{abstract}

\section{Anahtar Kelimeler \\ Robotik kol \\ Bulanık mantık kontrol \\ PID kontrol}

Keywords

Robotic arm

Fuzzy logic control

PID control

\section{Fuzzy Logic and PID control of a 3 DOF Robotic Arm}

\begin{abstract}
Nowadays, the robotic arms are used in many industrial applications. At this point, high precision control is required for robotics used in fields such as healthcare area. Therefore, the control method applied to robots is also important. In this study, a force was applied to the end function of a three degree-of-freedom robot and the robustness of the controllers are tested. PID and Fuzzy Logic control method are used for this process. The control process of robotic arm which is designed and simulated is obtained by using Fuzzy Logic and classical PID controllers and the results are presented comparatively.
\end{abstract}

\section{GİRIŞ (INTRODUCTION)}

Endüstriyel tesislerin ana bileșenleri haline gelen robot kolları, kaynak uygulamaları, malzemelerin taşınması, boyama işlemleri, paketleme, montaj, kesme, cilalama, yapıştırma, ameliyat gibi çok geniş bir alanda kullanım imkanına sahiptir. Günümüzde sanayi, endüstri, sağlık vb. birçok alanda tercih edilen robot kolları, insan hayatını kolaylaştırmak için vazgeçilmez araçlar haline gelmiştir. Robot kolları insan vücudundan esinlenerek insanların yaptığı işleri onlardan daha güçlü ve hassas bir şekilde yapabilen makinelerdir. $\mathrm{Bu}$ alanda yapılan çalışmalar gün geçtikçe artarken farklı serbestlik dereceli robot kolları farklı tasarımlar ile sunularak aynı zamanda farklı kontrol algoritmaları da kullanılmıştır. $\mathrm{Bu}$ noktada yapılan bir çalışma da, endüstriyel uygulamalarda kullanılan robotlar için yeniden programlanabilirlik, tekrarlanabilirlik, taşıma kapasitesi ve hız gibi özelliklerin olması gerektiği vurgulanmıștır [1]. Farklı serbestlik derecelerine sahip olan robot kolları ile ilgili yapılan çalışmalarda, bir bağlantıya sahip esnek bir robot kolu için yapılan bir araştırma da tasarım ve deneysel olarak araştırma yapılmış, mekanik özellikleri için uygun yapıyı elde edebilmek için sonlu elemanlar yöntemi tercih edilmiştir [2]. Benzer bir çalışma da, 2 serbestlik dereceli bir robot kolunun dinamik modelinin ortaya koyularak, adaptif sinirsel ağ tabanlı bulanık çıkarım sistemi ile bulanık kayma mod kontrol ile sistemin dayanıklılığı sağlanmıştır [3]. 3 serbestlik dereceli bir robot kolu ile ilgili bir çalışma da, sibernetik omuz diye adlandırılan sistem insan omzundan esinlenerek tasarlanmıştır [4]. Yeni kinematik yapıların 2, 3, 4 ve 5 serbestlik dereceli robotlar için gerçekleştirildiği bir diğer araştırma da ise, bu amaçla paralel mekanizmalar sunulmuştur [5]. Serbestlik derecesi arttıkça robot kolunun modellenmesi 
ve kontrolü zorlaşmaktadır. Ters kinematik problem çözümü yöntemleriyle ise birçok araştırma ortaya konulmuştur. Adaptif bir öğrenme algoritması kullanılarak ters kinematik problem çözümü yapılan bir çalışma da ise uçakta kullanılabilen bir robot kolu tasarlanmıştır ve konum kontrolü gerçekleştirilmiştir [6]. Bir diğer çalışma da, iki kollu 6 serbestlik dereceye sahip H20 mobil robotun konum kontrolü ve farklı özelliklere sahip tutucu uç tasarımı yapılmıştır [7]. ARMin II adlı rehabilitasyon robot kolunun mekanik yapısının ve kinematiğinin [8], insan kolunun referans alınarak üretildiği bir robot kolunun kinematik tasarımının [9], kendinden kalibrasyonlu insan kolu benzeri bir robot kolunun araştırıldığ1 [10] çalışmalarda ise 7 serbestlik dereceli robot kolları üzerine araştırmalar yapılmıştır. Robot kollarının mekanik aksamları, serbestlik derece sayısı ve yapısal özelliklerinin yanı sıra bu kolların kontrolü içinde birçok çalışma yapılmıştır. Akıllı sistemler yaygın olarak tercih edilen yöntemler arasındadır. Bulanık mantık tabanlı kontrol algoritmalarının tercih edildiği bir çalışma da, bulanık mantık tabanlı genelleştirilmiş kestirim kontrol yapısı robot kolu için uygulanmıştır [11]. Benzer bir araştırma da, bulanık mantık kontrol yapısı 2 serbestlik dereceli robot kolu için tasarlanırken, bu yapı için gerçekleştirilen kayma mod kontrol ve PID kontrol yapıları hakkında araştırmalar yapılarak karşılaştırmalı bir makale sunulmuştur [12]. Bulanık mantık kontrolün yanı sıra, adaptif yapay sinir ağları tabanlı kontrol kullanılarak insansı robot kontrolü [13], dayanıklı kontrolör tasarımı için bulanık mantık kayma mod kontrol tekniğinin uygulanması [14], yapay sinir ağları tabanlı genetik algoritma ile robot kollarının ters kinematiği ile hata minimizasyonu yapılması [15] gibi çalışmalar bu alanda gerçekleştirilen araştırmalardan sadece birkaçıdır.

$\mathrm{Bu}$ çalışma da ise, PID ve bulanık mantık yöntemleri ayrı ayrı 3 serbestlik dereceli robot kolunun kontrolü için kullanılarak, uç işlevciye uygulanan bir kuvvet etkisi altında kontrolörlerin performansları gözlemlenmiştir. $\mathrm{Bu}$ kuvvet, robot kolun çıkış karakteristiğini değiştirmekte ve kontrolünü zorlaştırmaktadır. Yöntemlerin performansları MATLAB-Simulink benzetim ortamı kullanılarak ortaya koyulmuş, sonuçlar grafikler ile verilip yöntemlerin başarımları değerlendirilmiştir.

\section{2. ÜÇ SERBESTLIKK DERECELİ ROBOT KOLU TASARIMI (DESIGN OF 3 DOF ROBOTIC ARM)}

3 serbestlik dereceli robot kolunun parçaları Solidworks programı kullanılarak bilgisayar ortamında çizilip, montajları yapılmıştır. Şekil.1'de tasarlanan ve çizimi yapılan robot kola ait ekran görüntüsü verilmiştir.

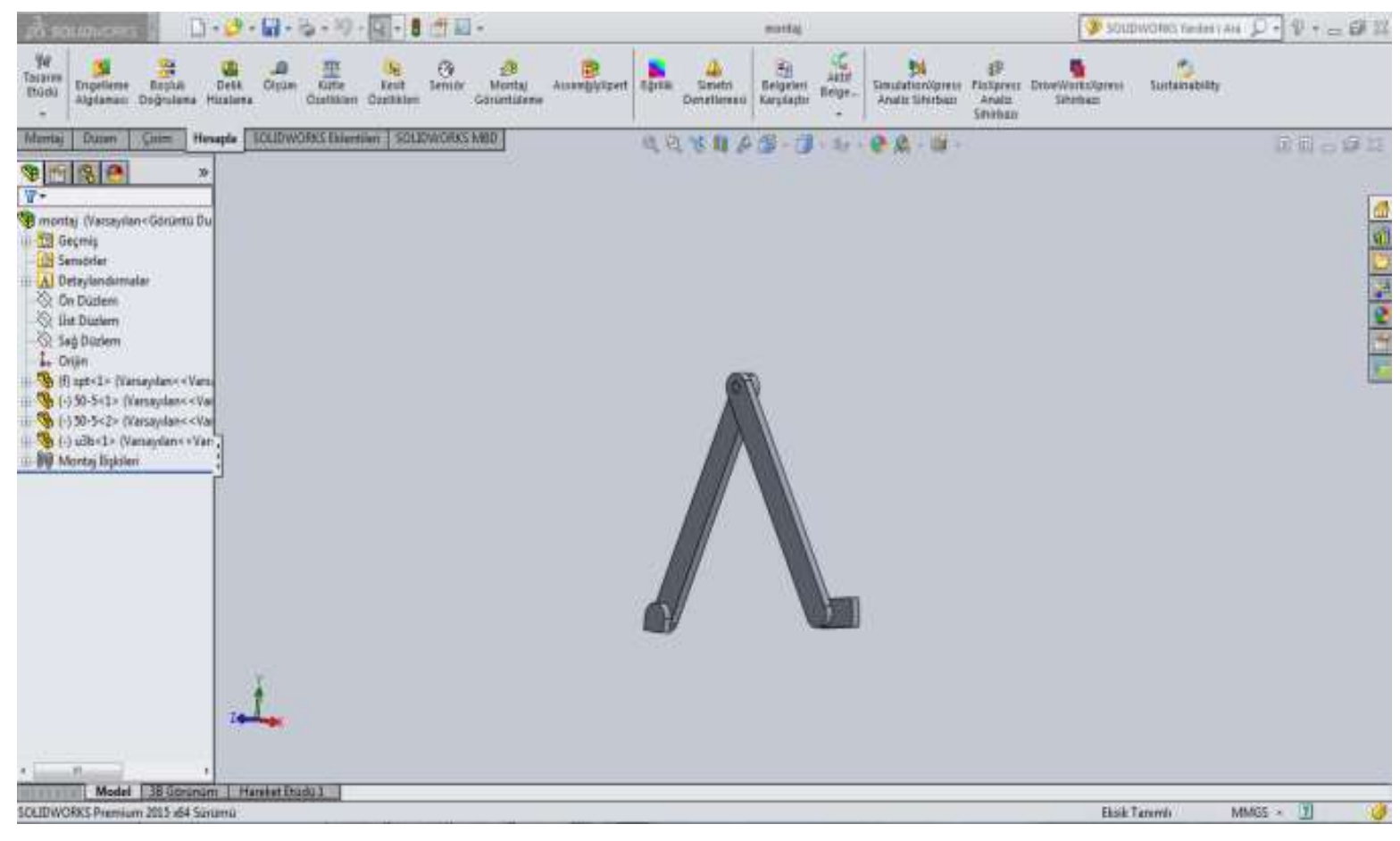

Şekil 1. Robot kol Solidworks modeli 
Bir sonraki aşamada, tasarımı ve montajı gerçekleştirilen robot kolunun Matlab modeli elde edilmiştir. Benzetim ortamına aktarılan tasarıma ait ekran görüntüsü ise Şekil 2.' de gösterilmiştir. Matlab programına aktarılan tasarım, Simulink yazılımında modellenmiş ve kontrol algoritmalarının uygulanacağı bir benzetim ortamı elde edilmiştir (Şekil.3). Robot kolun simulink modeline uygun bileşenler eklenerek her iki kontrol yöntemi de mekanizmaya uygulanmıştır.

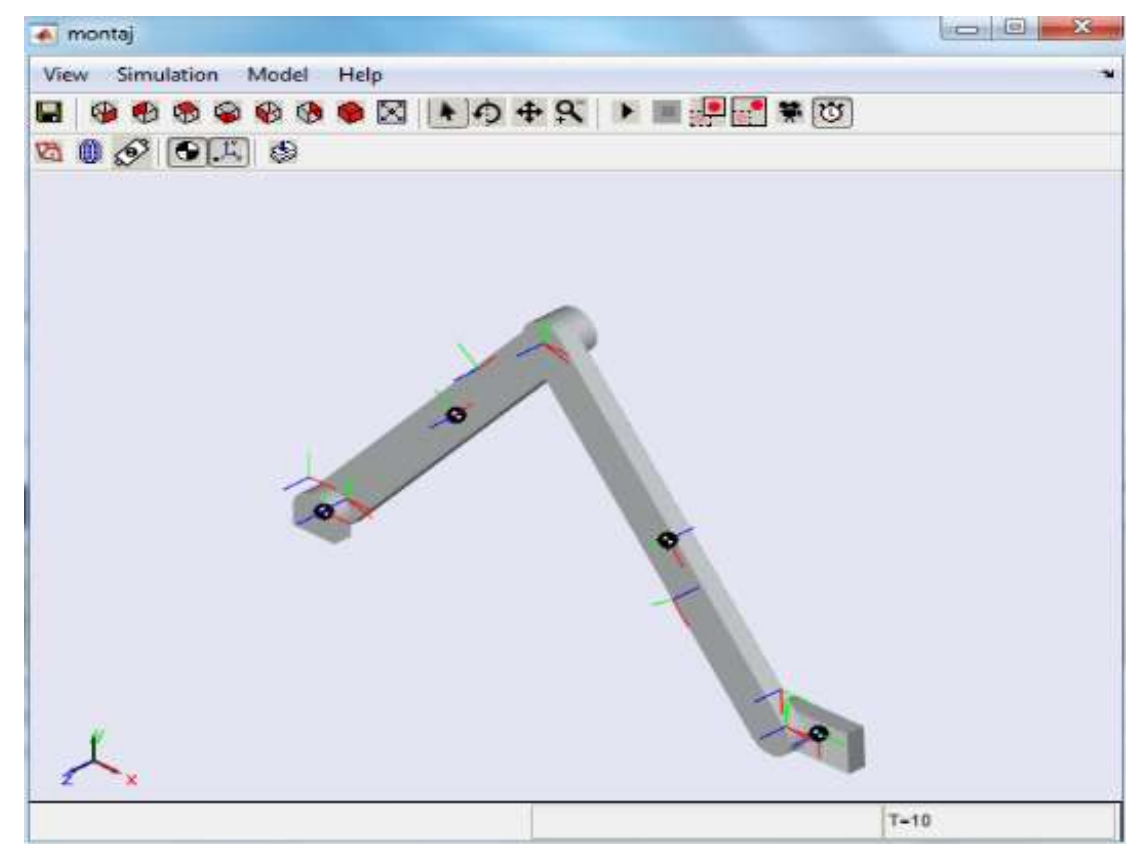

Şekil 2. Robot kol MATLAB modeli

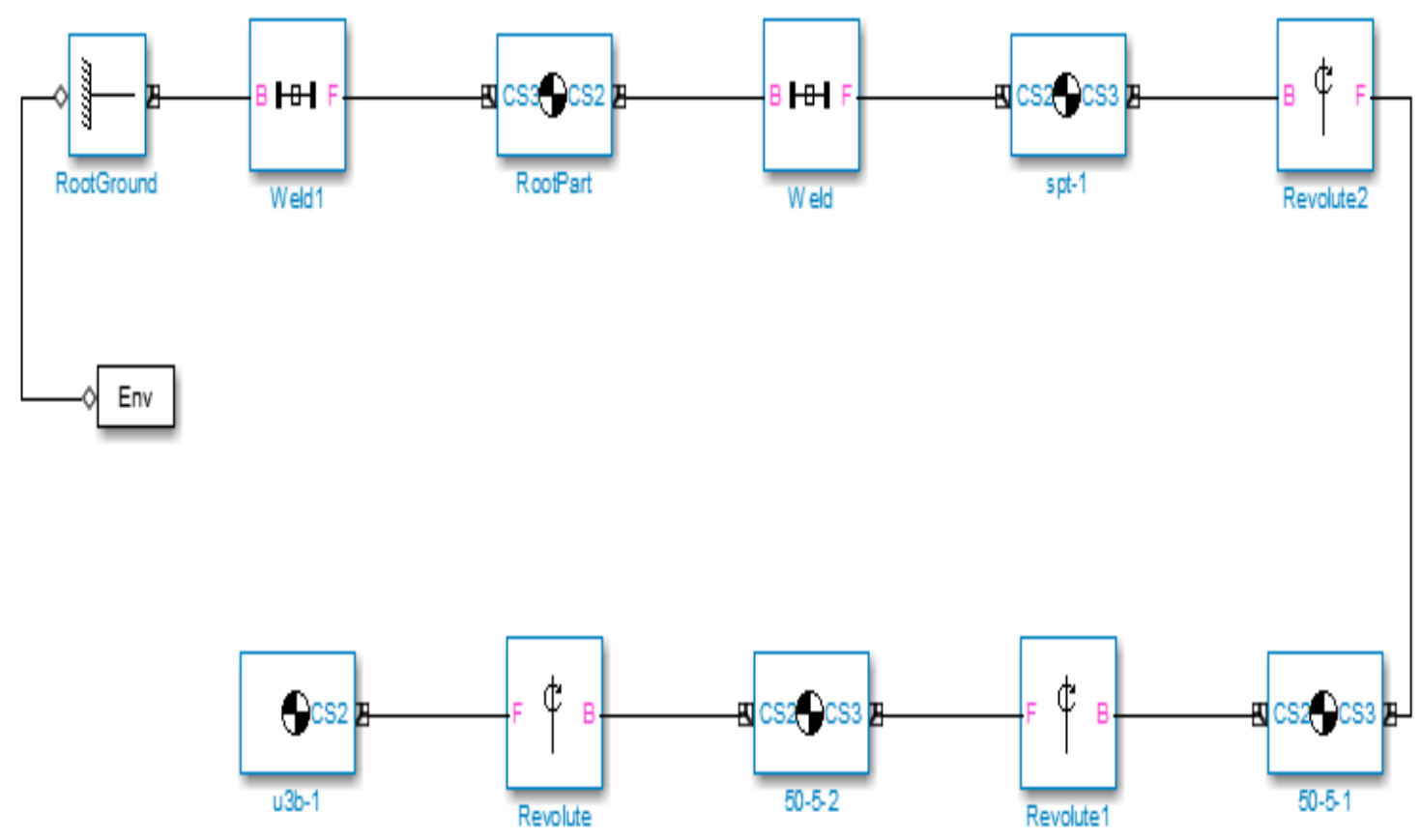

Şekil 3. Robot kol simulink modeli 


\section{KULLANILAN KONTROL YÖNTEMLERİ (THE USED CONTROL METHODS)}

Bu çalışmada, tasarlanan ve benzetim ortamına aktarılan robot kolun kontrolü için PID ve Bulanık mantık kontrol yöntemleri kullanılmıştır.

\subsection{PID Kontrol}

PID kontrol yöntemi oransal-integral-türevsel kontrolör olarak adlandırılır. Bu kontrol yöntemi, uygulama kolaylığı ve ucuz olması gibi sebeplerden dolayı endüstriyel alanlarda oldukça yaygın bir şekilde kullanılmaktadır. P, I ve D parametreleri her sistem için farklı değerler alacak şekilde belirli kurallar çerçevesinde ayarlanarak sistemin kontrolü sağlanır. PID kontrolörün cevabının genel ifadesi denklem.1'deki gibidir.

$u(t)=K p\left[e(t)+\frac{1}{T i} \int_{0}^{t} e(t) d t+T d \frac{d e(t)}{d t}\right]$

Burada, Kp oransal sabit katsayısı, Ti integral katsayısı ve Td türev katsayısıdır. P, I ve D değerlerinin belirlenmesinde birkaç yöntem kullanılmaktadır. Bunlardan bir kısmı uzun matematiksel hesaplama yöntemi ile bir kısmı ise belirli kurallara göre tahmini değerler vererek elde etme esasına dayanır. Ancak PID parametre değerlerinin hesaplanmasında çok kullanışlı olan ve bu çalışmada da uygulayacağımız yöntem Matlab Simulink programında mevcut olan bir araçtır. Bu komut kullanılarak birkaç kriter dikkate alınıp kısa sürede P, I ve D parametrelerinin hesaplanması mümkün olmaktadır. Şekil 4' te PID kontrolör ile robot kolun denetiminin gerçekleştirildiği benzetim şeması gösterilmiştir.

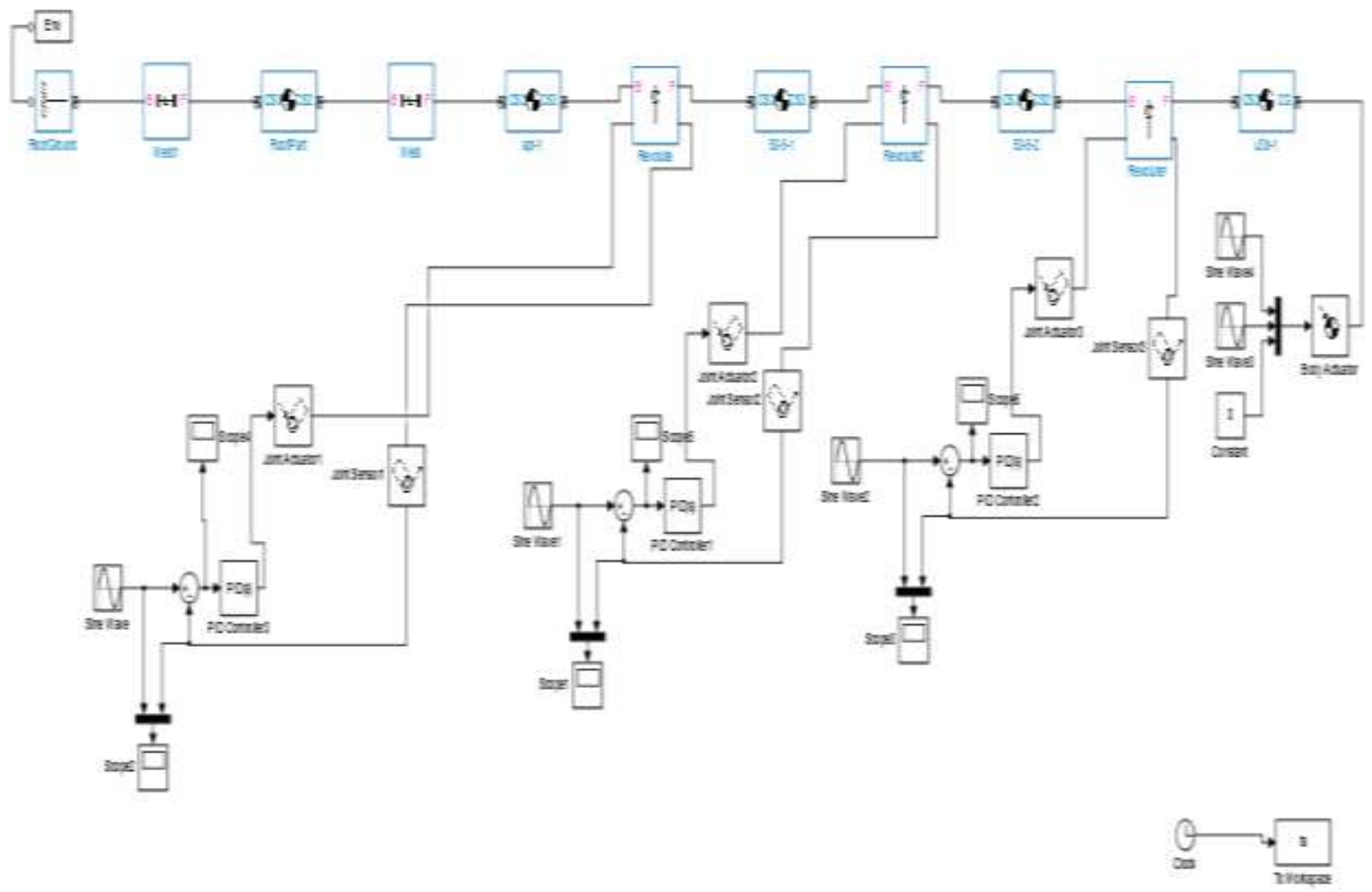

Şekil 4. Matlab Simulink ortamında PID kontrolör ile robot kolun denetimi

PID kontrolör sanayide çok fazla kullanılmasına rağmen pratikte bazı dezavantajları da mevcuttur. Basit yapısına rağmen matematiksel modele ihtiyaç duyması ve doğrusal olmayan sistemlerde başarılı sonuçlar verememesi, bozucu etkenlerden dolayı değişen çevre şartlarına uyum sağlayamaması bu kontrol yönteminin dezavantajları olarak gösterilmektedir. 


\subsection{Bulanık Mantık Kontrol}

Bulanık mantık; yapay zeka yöntemlerinden biri olup temelinde insan düşünme yapısı vardır. Bulanık mantık kontrol yönteminde klasik anahtarlama mantığından (0 ve 1) farklı olarak ara değerlerde mevcuttur. Genel olarak insanlara has sözel ifadelerden faydalanılarak ve uzman tecrübesine dayanılarak kontrolör tasarlanmaktadır. Yani bu yöntemin temeli sayısal ifadelerin yerine sözel ifadeler arasında mantıksal ilişki kurmaya dayanmaktadır. Büyüklükler büyük pozitif, pozitif, sıfır, negatif, büyük negatif gibi adlandırılmaktadır. Bu yöntemde, kontrol edilecek sistemin matematiksel modeline ihtiyaç duyulmaz. Bu sayede matematiksel modelinin çıkarılması çok zor olan sistemlerin insan vücudu gibi çok serbestlik dereceli ve kompleks yapıların modellemesinde oluşan zorlukların ve modellense dahi gözden kaçan hataların önüne geçebilme imkanı sağlanması söz konusudur. Sisteme uygulanacak sayısal girişlere karşı oluşacak çıkış değerleri elde edilmektedir.

Sayısal veriler bulanıklaştırılıp referans değere olan yakınlık ve uzaklıkları arasındaki ilişkilere göre birer isim verilerek bir sinıflandırma yapılır. Kural tablosunda bu sinıflandırma kullanılarak her bir giriş değerine uygun işlemler gerçekleştirilip uygun çıkış üretilmekte ve sistemin daha verimli kullanılması sağlanmaktadır. Örneğin hata pozitif büyükse bu hatayı hızlı bir şekilde referans değere çekmek için pozitif büyük çıkışı sisteme gönderilmelidir. Hata negatif küçükse bu değere de negatif küçük sinyali uygulanarak giriş sinyaline uygun bir çıkış sinyali verilip daha etkili bir kontrol sağlanmış olur. Bu mantık çerçevesinde bir kural tablosu oluşturularak sistemi kontrol edebilecek bir kontrol mekanizması oluşturulur. Oluşturulan bu kural tablosuyla sisteme uygulanan giriş değerlerine karşı sistemin nasıl bir çıkış değeri vermesi gerektiği belirlenir. Robot kol mekanizmasında kullanılan kurallar Tablo 1.' deki gibidir.

Tablo 1. Kural tablosu

\begin{tabular}{|c|c|c|c|}
\hline de le & $\mathrm{N}$ & $\mathrm{Z}$ & $\mathrm{P}$ \\
\hline $\mathrm{N}$ & $\mathrm{N}$ & $\mathrm{N}$ & $\mathrm{Z}$ \\
\hline $\mathrm{Z}$ & $\mathrm{N}$ & $\mathrm{Z}$ & $\mathrm{P}$ \\
\hline $\mathrm{P}$ & $\mathrm{Z}$ & $\mathrm{P}$ & $\mathrm{P}$ \\
\hline
\end{tabular}

Bulanık mantık kontrol algoritmasının hangi aşamalara sahip olduğu bloklar halinde Şekil 5' te verilmiştir.

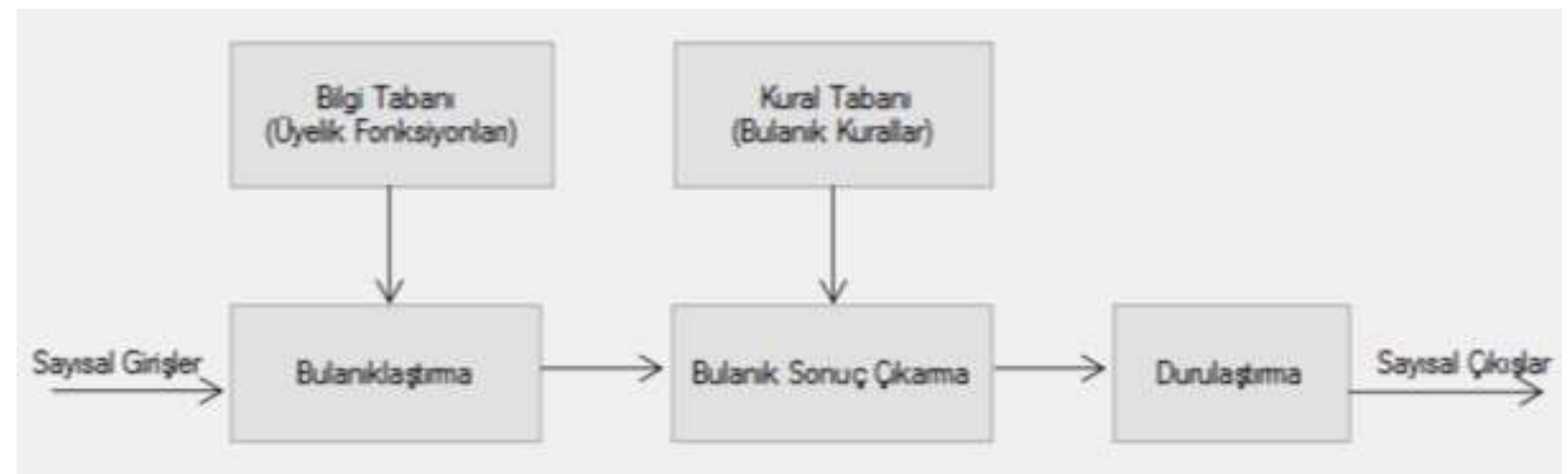

Şekil 5. Bulanık Mantık Blok Diyagramı

Bulanıklaştırma birimi: Sisteme girdi olarak gönderilen sayısal verileri sözel ifadelere çeviren birimdir. 
Bilgi Tabanı: Uygulanacak sistemin etkilendiği giriş verilerini ve bunlar hakkındaki bilgilerin tamamını içerir. $\mathrm{Bu}$ yapıya bilgi tabanı adı da verilir. Sistemin çalışması için gerekli giriş verilerinin sistemde kullanılmasını sağlar.

Kural Tabanı: Veri tabanındaki girişleri çıkış değişkenlerine bağlayan mantıksal, (IF - THEN) türünde yazılabilen kuralları içermektedir. Bu kuralların yazılmasında sadece giriş verileri ile çıkışların arasında mümkün olabilen tüm ihtimaller kural tabanında(rule base) ifade edilir. Eğer kural tabanı oluşabilecek ihtimallerden eksik veri içeriyorsa sistem hata verir. Her bir kural girdi uzayının bir parçasını çıktı uzayına mantıksal olarak bağlar sonuç olarak bu kuralların tümü tabanını oluşturur.

Bulanık Sonuç Çıkarma Birimi: Sisteme uygulanan bulanık giriş değerini bilgi tabanı ve kural tabanındaki verileri kullanarak bulanık bir sonuç çıkaran birimdir.

Durulaştırma: Bulanık sonuç çıkarma biriminden gelen bulanık verilerin yani sözel verilerin makinelerin anlayabileceği sayısal verilere çevrildiği işlemdir [16].

Robot kolun bulanık mantık ile kontrolüne ait benzetim ortamının yapısı Şekil 6' da gösterilmiştir.

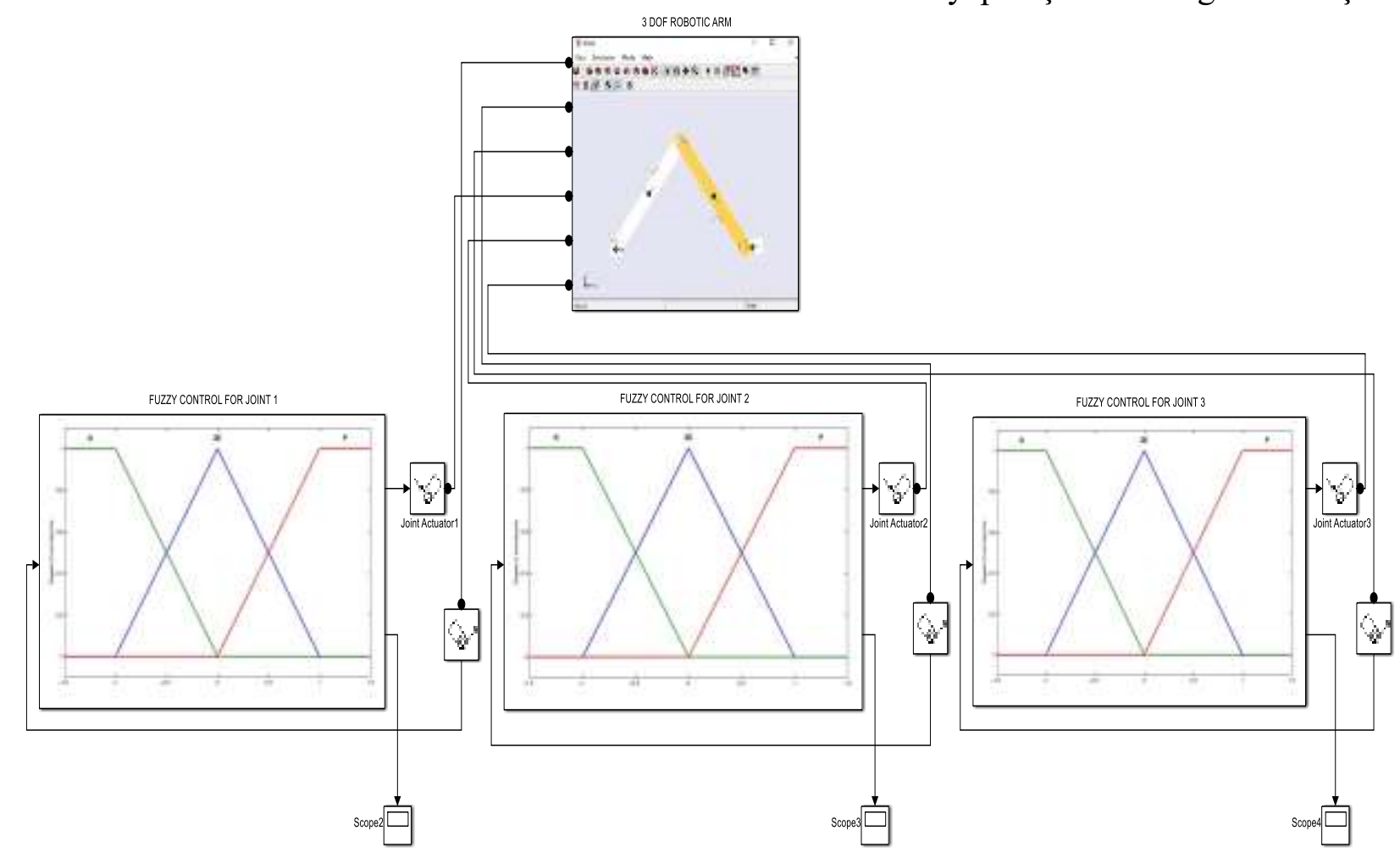

Şekil 6. Robot kolun bulanık mantık ile kontrolü

Bulanık mantık kontrol yönteminde sisteme uygulanan referans sinyali ile gerçek değer Şekil.7' deki gibi karşılaştırılmaktadır. Bu iki sinyal arasındaki fark hata bilgisidir. Sistemde oluşan hata değeri ve bu hatanın türevi bulanık mantık kontrolörün girişine uygulanmaktadır.

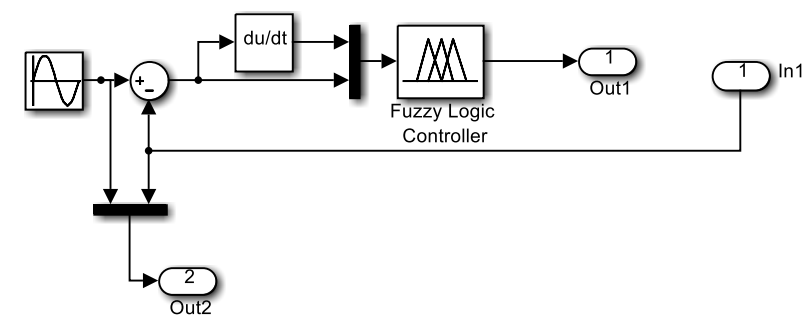

Şekil 7. Bulanık mantık kontrolör benzetim şeması 


\section{SONUÇ ve TARTIȘMA (CONCLUSION and DISCUSSION)}

Kullanılan iki kontrolöre ait sonuçlar, PID ve Bulanık Mantık kontrolörler için sırasıyla verilmiş ve elde edilen sonuçlar grafikler halinde sunulmuştur.

\section{PID Kontrol}

3 serbestlik dereceli robot kolunun kontrolü PID kontrol ile gerçekleştirildiğinde dışardan herhangi bir etki olmadığı ya da mevcut şartların stabil kaldığı sürece çok küçük bir kararlı hal hatasıyla çok iyi bir kontrol performansı sağlanmaktadır. Sistemin ve kontrolörün başarımı ise sinüsoidal referans girişler için test edilmiştir.

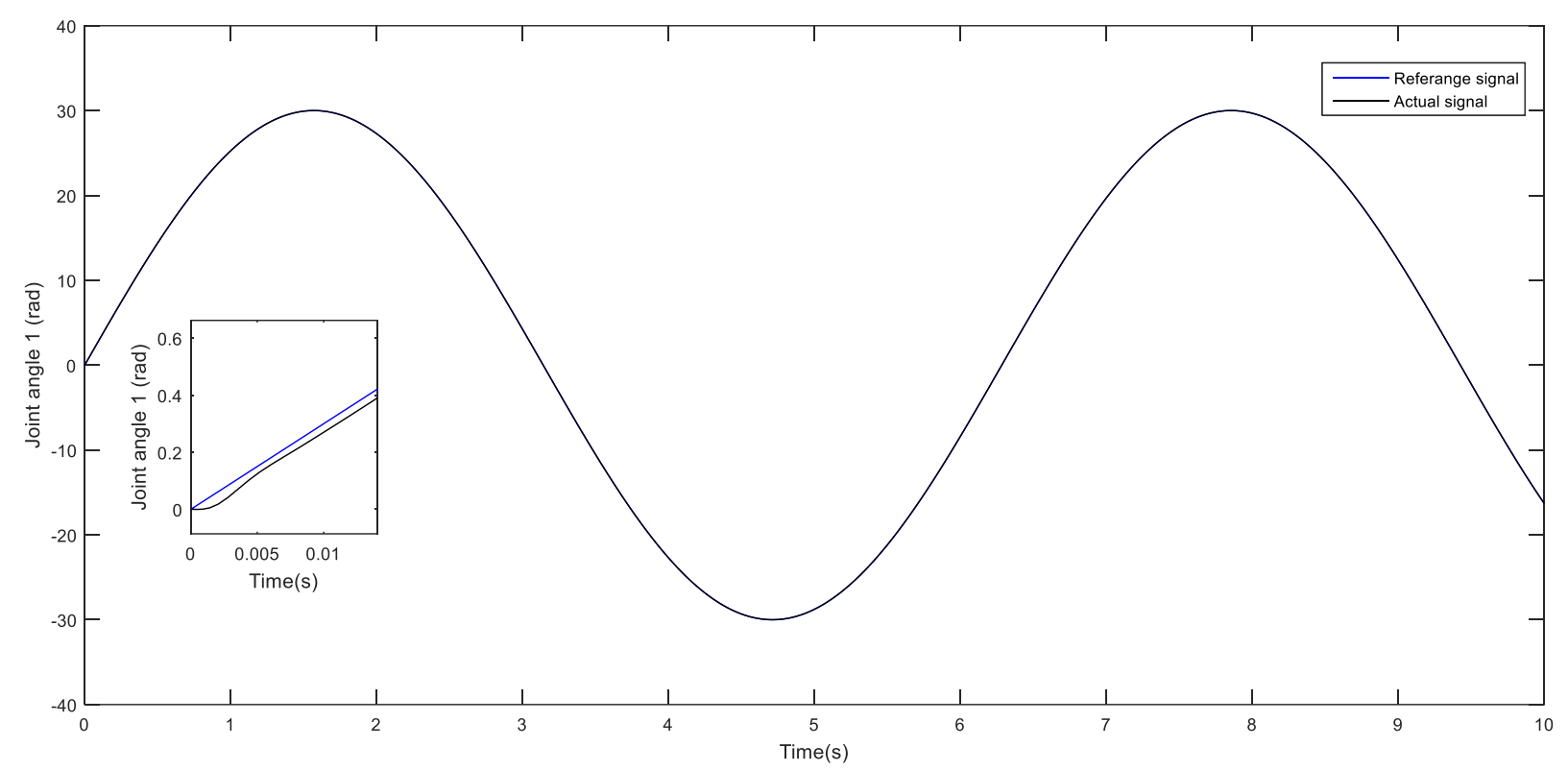

Şekil 8. Birinci mafsala uygulanan referans sinyali ve gerçek sinyal

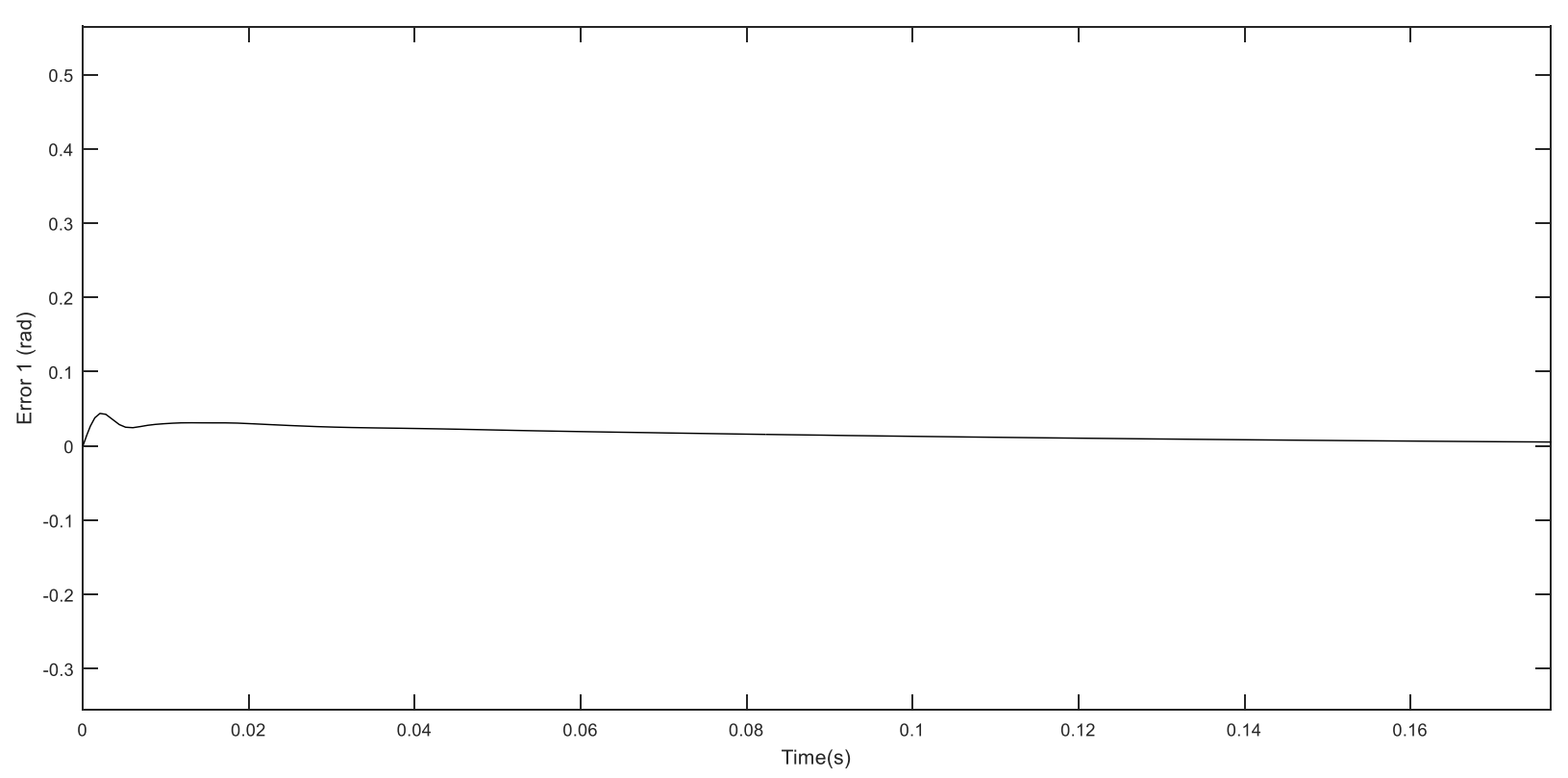

Şekil 9. Birinci mafsala ait hata sinyali 


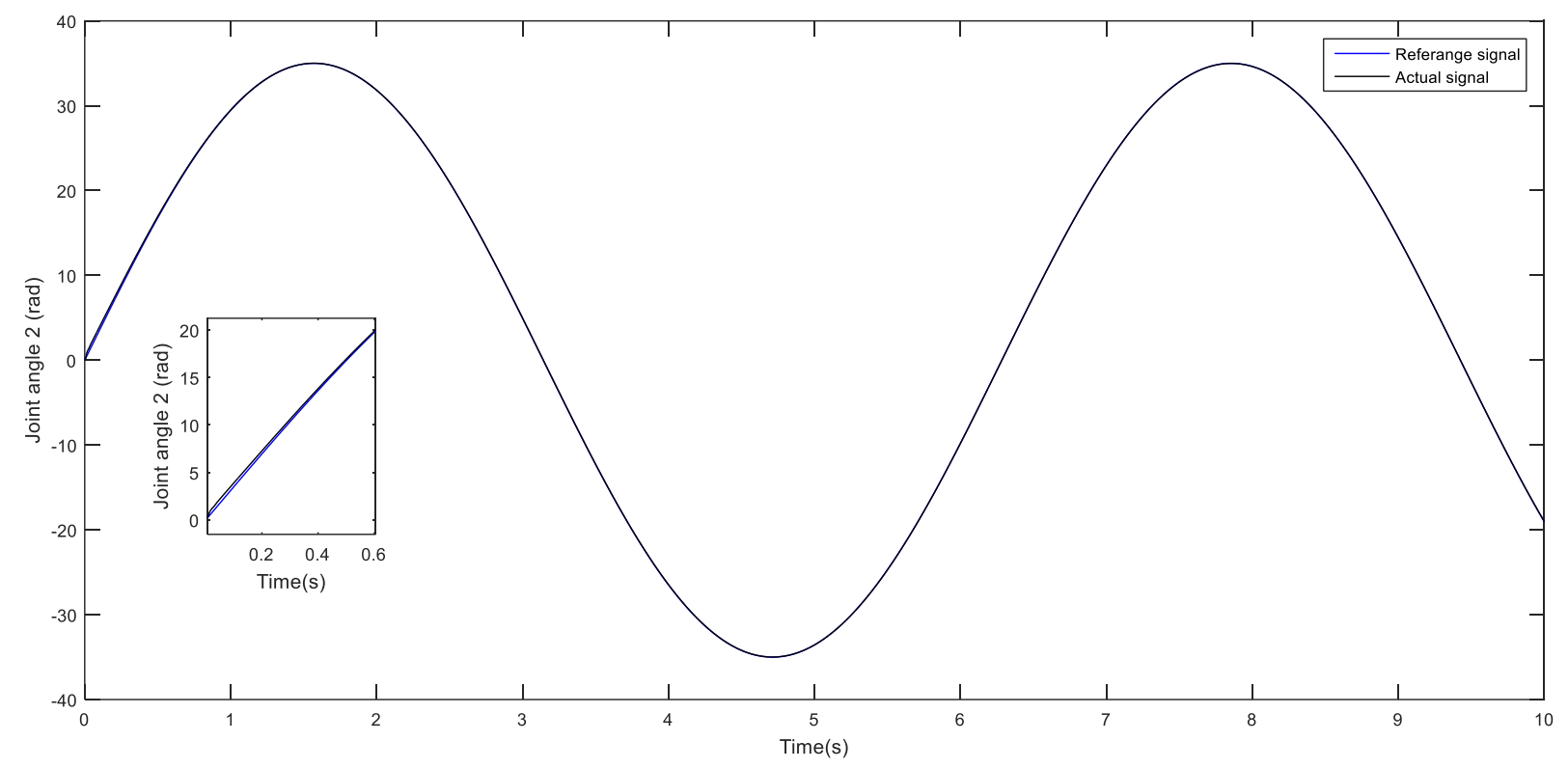

Şekil 10. Íkinci mafsala uygulanan referans sinyali ve gerçek sinyal

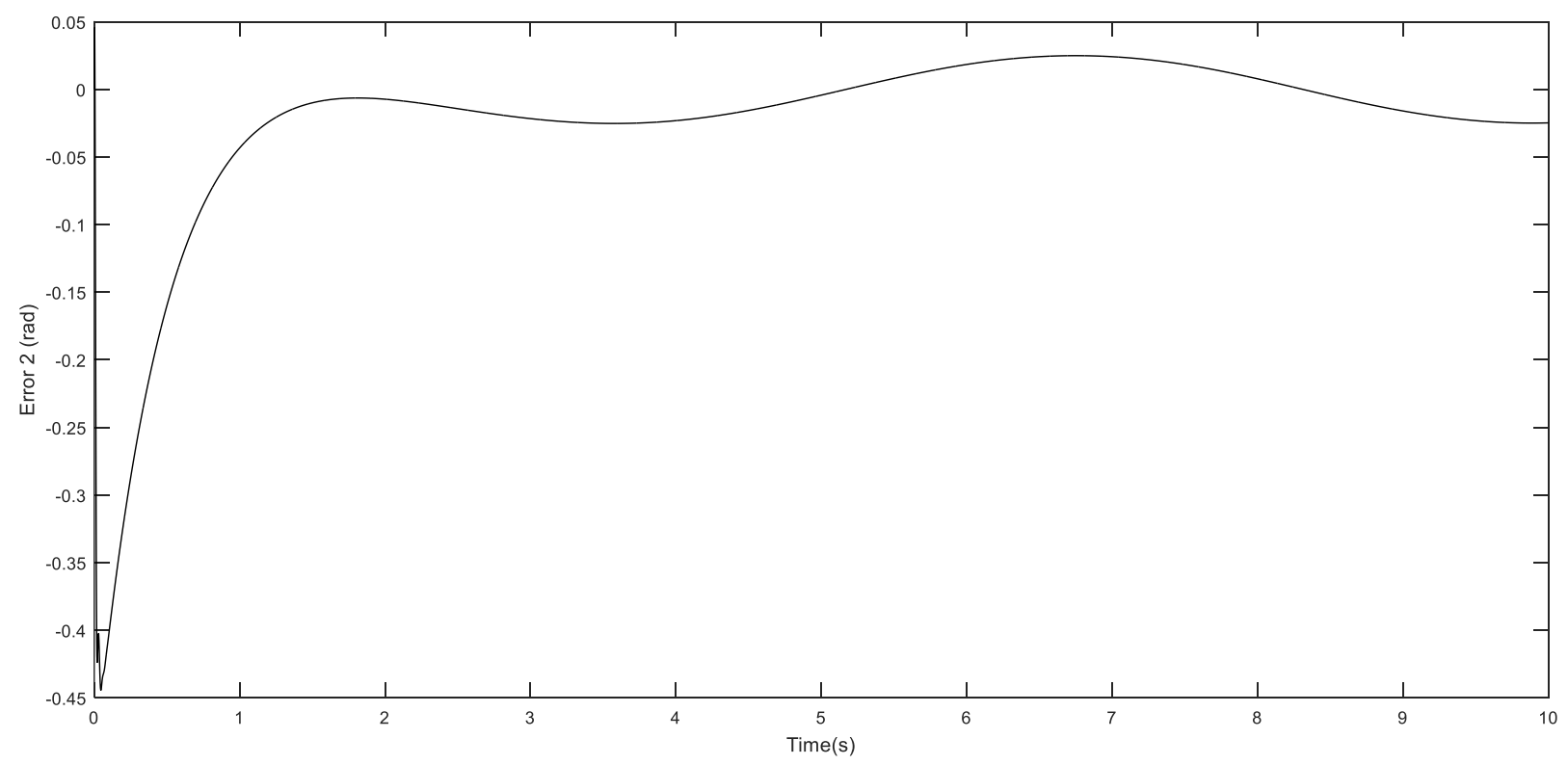

Şekil 11. İkinci mafsala ait hata sinyali 


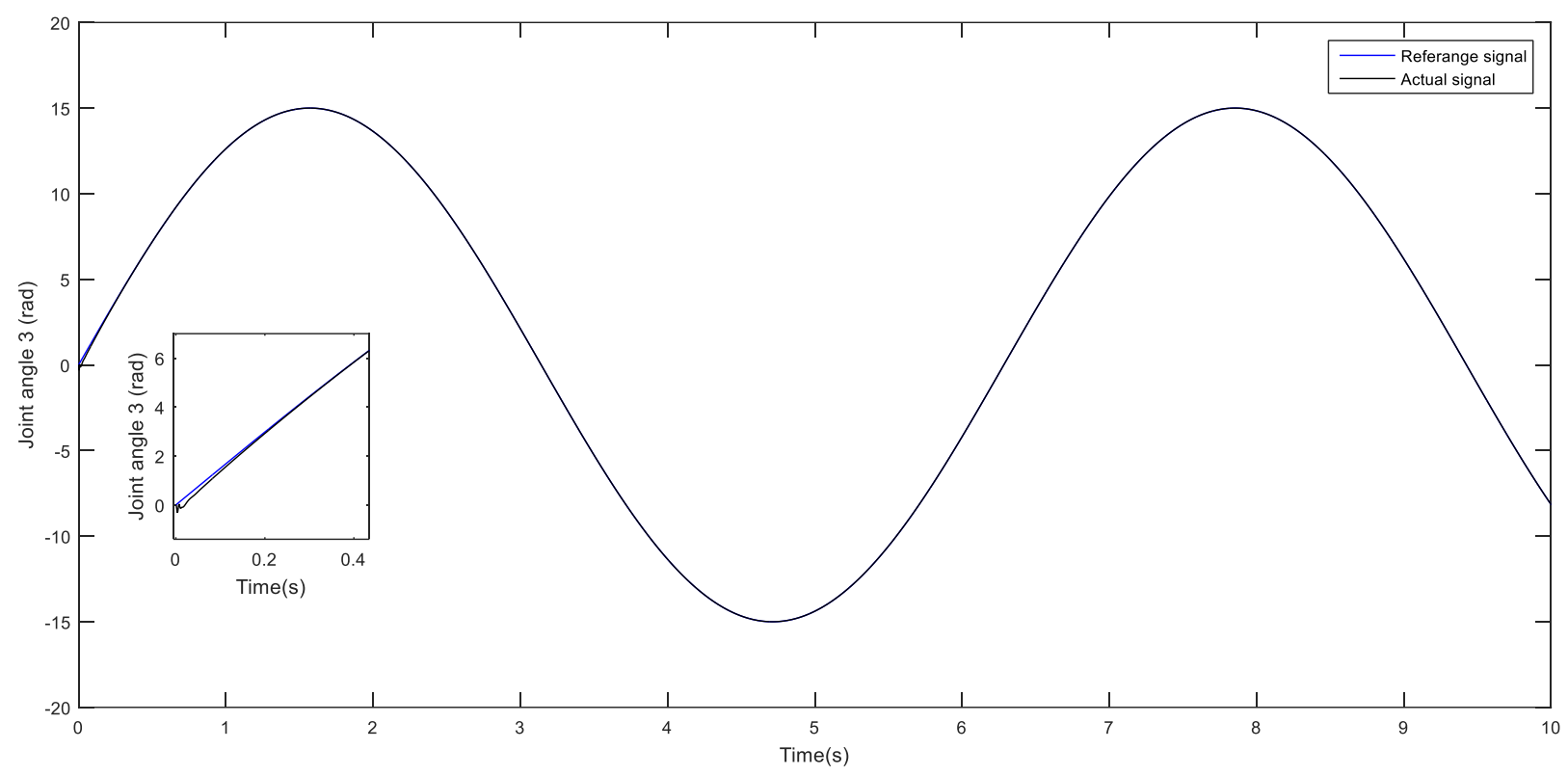

Şekil 12. Üçüncü mafsala uygulanan referans sinyali ve gerçek sinyal

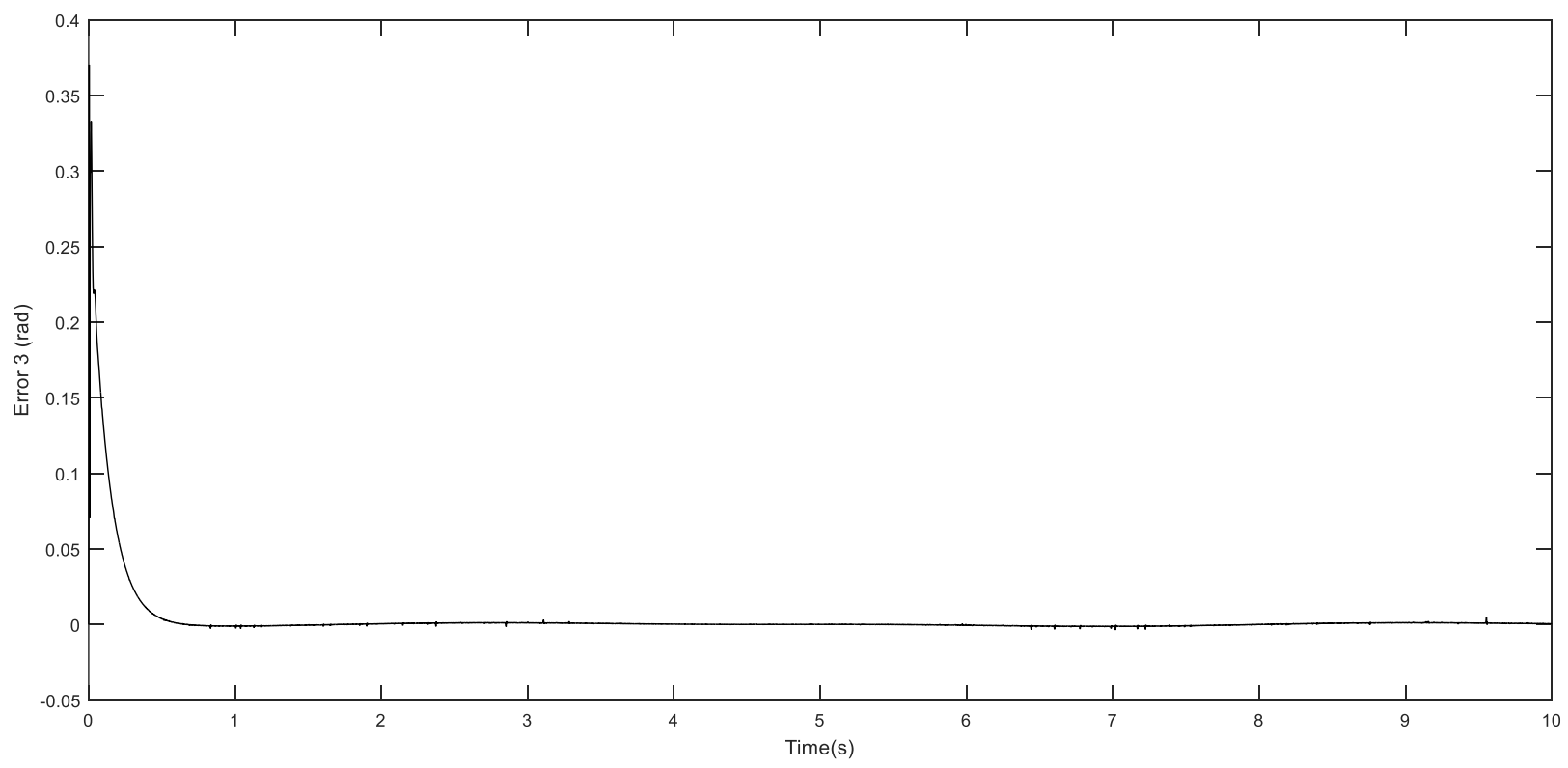

Şekil 13. Üçüncü mafsala ait hata sinyali

\section{Bulanık Mantık Kontrol}

Sisteme uygulanan Bulanık Mantık kontrolünden sonra her bir mafsal için aşağıdaki sonuçlar elde edilmiştir. Bu grafiklerde görüldügü gibi herhangi bir kararlı hal hatası yoktur. Ancak çıkış sinyali referans sinyalinin etrafında bir salınım yapmaktadır. Sisteme çok ani kuvvetler uygulanmadığ 1 sürece değişken kuvvetlerde de etkili kontrol sağlamaktadır. Ayrıca bu kontrolörün kullanılabilmesi için yüksek hızda işleme kabiliyeti gerekmektedir. Daha düşük örnekleme frekansı performansı artırmaktadır. 


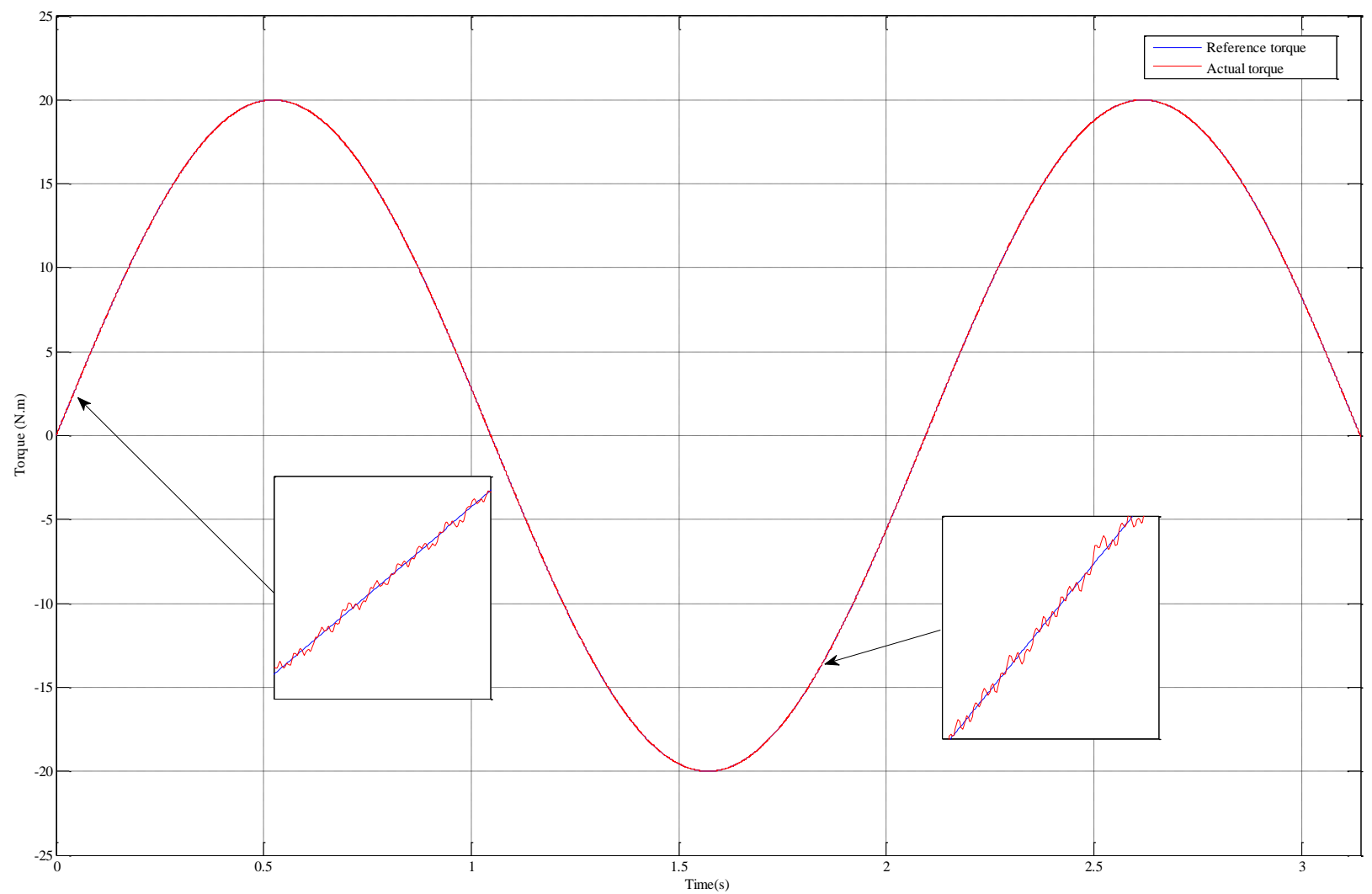

Şekil 14. Birinci mafsala uygulanan referans sinyali ve gerçek sinyal

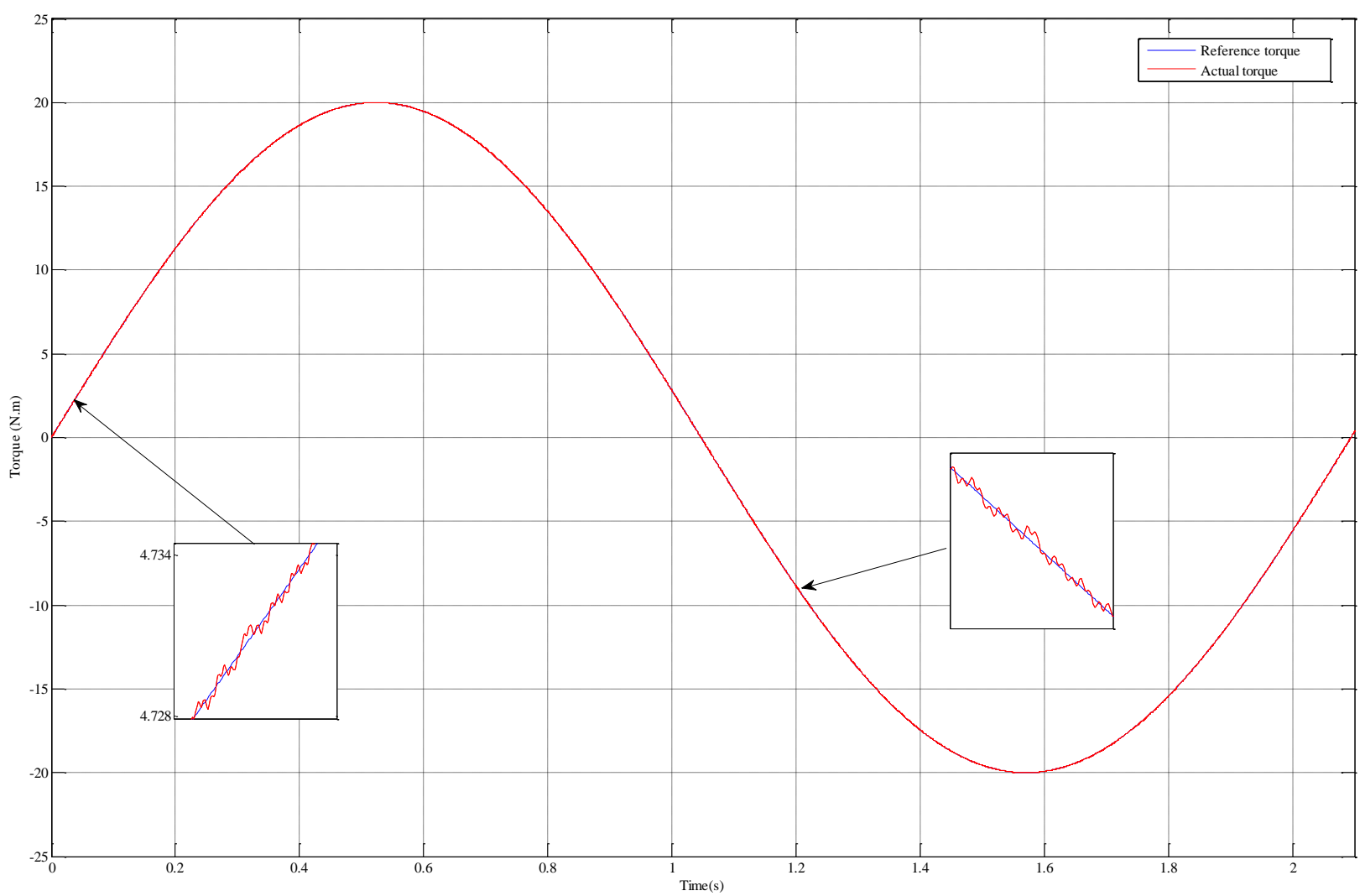

Şekil 15. İkinci mafsala uygulanan referans sinyali ve gerçek sinyal 


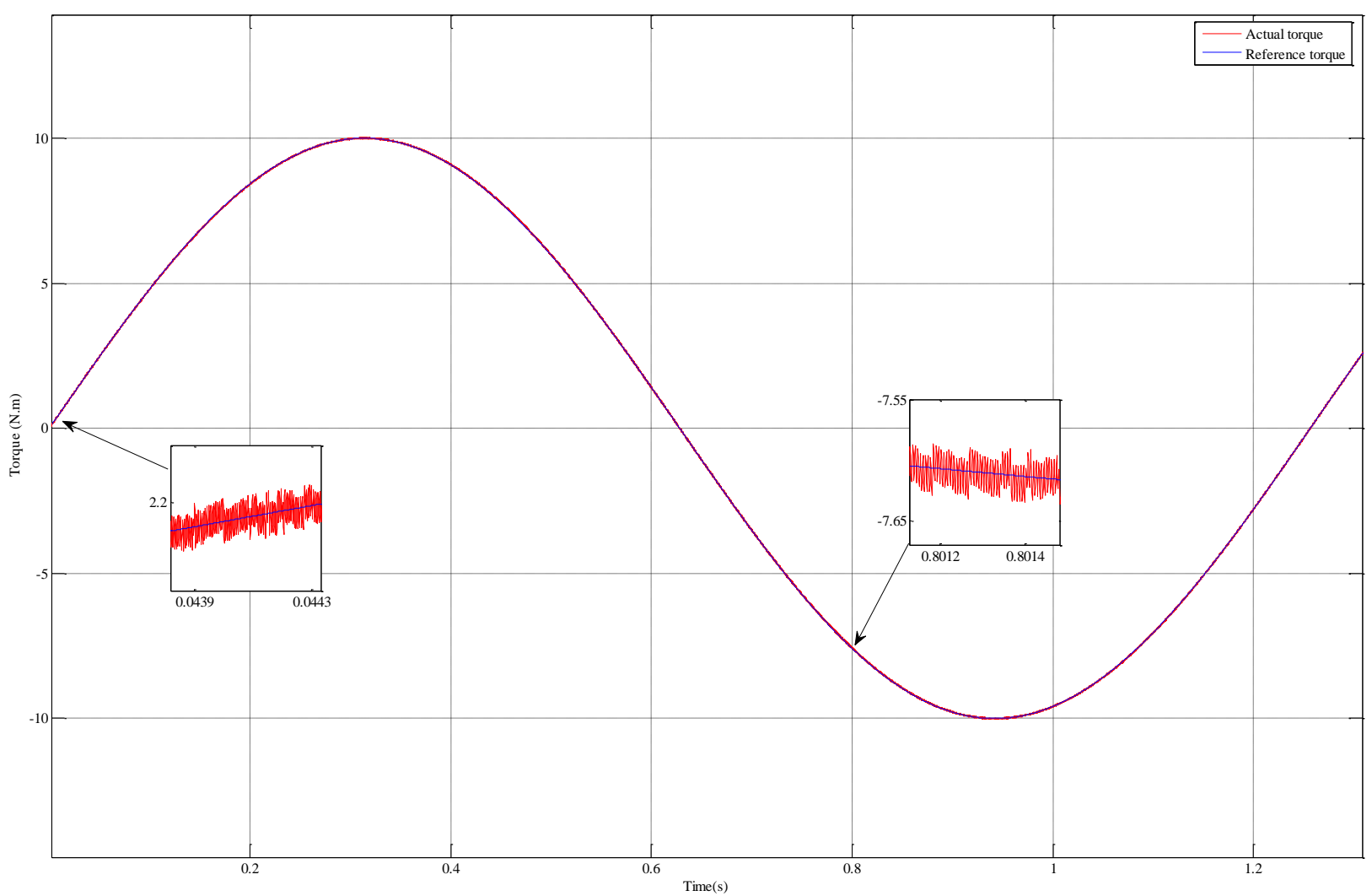

Şekil 16. Üçüncü mafsala uygulanan referans sinyali ve gerçek sinyal

Sonuç olarak, solidworks programı kullanılarak tasarlanan ve çizilen 3 serbestlik dereceli robot kolu, MATLAB Simulink programına aktarılmış ve kontrol işlemleri için PID ve bulanık mantık kontrolör kullanılmıştır. Her iki yöntem içinde elde edilen sonuçlar tatmin edicidir ve verilen grafiklerde bu durum görülmektedir.

\section{KAYNAKLAR (REFERENCES)}

[1] S. Yumurtac1 and T. Mert, "Robotik Kaynak Sistemleri ve Gelişme İstikametleri," Mühendis ve Makine, vol. 44, no. 526, pp. 32-40, 2003.

[2] B. V. Chapnik, G. R. Heppler and J. D. Aplevich, "Modeling Impact on A One-Link Flexible Robotic Arm," IEEE Transactions on Robotics and Automation, vol. 7, no. 4, pp. 479-488, 1991.

[3] M. Ö. Efe, "Fractional Fuzzy Adaptive Sliding-Mode Control of a 2-DOF Direct-Drive Robot Arm," IEEE Transactions on Systems, Man, and Cybernetics, Part B (Cybernetics), vol. 38, no. 6, pp. 1561$1570,2008$.

[4] M. Okada and Y. Nakamura, "Development of A Cybernetic Shoulder-A 3-Dof Mechanism that Imitates Biological Shoulder Motion," IEEE Transactions on Robotics, vol. 21, no. 3, pp. 438-444, 2005.

[5] F. Gao, W. Li, X. Zhao, Z. Jin and H. Zhao, "New Kinematic Structures for 2-, 3-, 4-, and 5-DOF Parallel Manipulator Designs," Mechanism and Machine Theory, vol. 37, no. 11, pp. 1395-1411, 2002. 
[6] A. T. Hasan, A. S. Hamouda, N. Ismail and H. A. Al-Assadi, "An Adaptive-Learning Algorithm to Solve The Inverse Kinematics Problem of A 6 D.O.F Serial Robot Manipulator," Advances in Engineering Software, vol. 37, no. 7, pp. 432-438, 2006.

[7] M. A. Mohammed, L. Hui, S. Norbert and T. Kerstin, "Multiple Lab Ware Manipulation in Life Science Laboratories using Mobile Robots," in 17th International Conference on MechatronicsMechatronika (ME), Prague, 2016.

[8] M. Mihelj, T. Nef and R. Riener, "ARMin II - 7 DoF rehabilitation robot: mechanics and kinematics," in IEEE International Conference on Robotics and Automation, Roma, 2007.

[9] G. Yang, W. Lin, M. S. Kurbanhusen, C. B. Pham and S. H. Yeo, "Kinematic Design of A 7-DOF Cable-Driven Humanoid Arm: A Solution-in-Nature Approach," in IEEE/ASME International Conference on Advanced Intelligent Mechatronics, Monterey, 2005.

[10] S. K. Mustafa, G. Yang, S. H. Yeo, W. Lin and I. M. Chen, "Self-Calibration of a Biologically Inspired 7 DOF Cable-Driven Robotic Arm," in EEE/ASME Transactions on Mechatronics, 2008.

[11] J. Cronin, J. M. Escano, S. Roshany-Yamchi and N. Canty, "Fuzzy-Based Generalized Predictive Control of a Robotic Arm," in 25th IET Irish Signals \& Systems Conference, 2014.

[12] K. Lochan and B. K. Roy, "Control of Two-link 2-DOF Robot Manipulator Using Fuzzy Logic Techniques: A Review," in Fourth International Conference on Soft Computing for Problem Solving, Warsaw, 2014.

[13] Z. Liu, C. Chen, Y. Zhang and C. L. Chen, "Adaptive Neural Control for Dual-Arm Coordination of Humanoid Robot With Unknown Nonlinearities in Output Mechanism," IEEE Transactions on Cybernetics, vol. 45, no. 3, pp. 507-518, 2014.

[14] F. Piltan, A. Nabaee, M. Ebrahimi and M. Bazregar, "Design Robust Fuzzy Sliding Mode Control Technique for Robot Manipulator Systems with Modeling Uncertainties," International Journal of Information Technology and Computer Science, vol. 5, no. 8, pp. 123-135, 2013.

[15] R. Koker, "A genetic algorithm approach to a neural-network-based inverse kinematics solution of robotic manipulators based on error minimization," Information Sciences, vol. 222, no. 10, pp. 528543, 2013.

[16] A. Eleren, "IMKB' ye Kayıtlı Çimento İşletmelerinin Finansal Tablolarının Bulanık Mantık Yaklaşımı ile Değerlendirilmesi," Afyon Kocatepe Üniversitesi, I.I.B.F. Dergisi, vol. 9, no. 1, pp. 141-153, 2007.

[17] H.-T. Kang and C. J. Yoon, "Neural Network Approaches to Aid Simple Truss Design Problems," Computer-Aided Civil and Infrastructure Engineering, vol. 9, no. 3, pp. 211-218, 1994.

[18] M. Fırat and M. Güngör, "Askı Madde Konsantrasyonu ve Miktarının Yapay Sinir Ağları ile Belirlenmesi," IMO Teknik Dergi, vol. 15, no. 73, pp. 3267-3282, 2015.

[19] Y. K. Demir, Yapay Sinir Ağları ile Ulaştırma Taleplerinin Modellenmesi, İstanbul: İTÜ Fen Bilimleri Enstitüsü, Yüksek Lisans Tezi, 1997. 